\title{
Incidence and Clinical Characteristics of Congenital Heart Disease among Neonates in Neonatal Intensive Care Unit
}

\author{
Ufuk Kursat Korkmaz ${ }^{1}$, Esra Akyuz Ozkan ${ }^{2, *}$, Ayse Neslin Akkoca ${ }^{3}$, Ebru Sivaslioglu ${ }^{4}$ \\ ${ }^{1}$ Abant Izzet Baysal University Medical Faculty, Department of Cardiovascular Surgery, Bolu, Turkey \\ ${ }^{2}$ Bozok University Medical Faculty, Department of Pediatrics, Yozgat, Turkey \\ ${ }^{3}$ Iskenderun State Hospital, Department of Family Medicine, Hatay, Turkey \\ ${ }^{4}$ Iskenderun Family Health Center, Hatay, Turkey
}

Email address:

esra.akyuz@mynet.com (E. A. Ozkan)

\section{To cite this article:}

Ufuk Kursat Korkmaz, Esra Akyuz Ozkan, Ayse Neslin Akkoca, Ebru Sivaslioglu. Incidence and Clinical Characteristics of Congenital Heart Disease among Neonates in Neonatal Intensive Care Unit. American Journal of Health Research. Vol. 3, No. 3, 2015, pp. 161-165.

doi: 10.11648/j.ajhr.20150303.19

\begin{abstract}
Background: Congenital heart diseases affect a large number of newborns and account for a high proportion of infant mortality worldwide. There are regional differences in the prevalence and distribution pattern of congenital heart diseases. We aimed to evaluate the relative frequencies, risk factors and diagnostic clues of congenital heart disease in newborns at our neonatal intensive care unit. Materials and methods: Among 326 cases admitted to the Abant Izzet Baysal University Neonatal Intensive Care Unit between February 2013 - September 2014, thirty-five newborns with congenital heart disease were evaluated, retrospectively. Data was collected on a predesigned proforma containing information regarding gender, gestational age and weight at birth, family history, and associated malformations. Results: The prevalence of congenital heart disease was $10.7 \%$. The most common cause for cardiology consultation was cardiac murmur $(85.5 \%)$. The relative percentage of acyanotic and cyanotic heart defects were $91.6 \%$ and $8.4 \%$, respectively. The most frequent acyanotic defect was ventricular septal defect with a prevalence of $22.8 \%$. Maternal diabetes mellitus and Down syndrome were observed in $17.1 \%$ and $2.8 \%$ of cases, respectively. Conclusion: The prevalence of congenital heart disease in newborns at the neonatal intensive care unit was higher than that in all live births and most common defect was muscular VSD. The most frequent diagnostic clue was cardiac murmur.
\end{abstract}

Keywords: Congenital Heart Diseases, Echocardiography, Neonatal Intensive Care Unit, Newborn

\section{Introduction}

Congenital heart diseases (CHDs) are the most common congenital fetal malformations and are responsible for a high rate of child mortality and morbidity. While prenatal incidence of CHD ranges from 2.4 to $52 \%$ (1-6), postnatal incidence is around 0.3 to $1.2 \%$ of live births $(7,8)$. CHD is more frequent in neonates in the neonatal intensive care unit than in live born neonates in population. Shima $\mathrm{Y}$ et al suggested that the occurrence rate of CHD was approximately $4.5 \%$ of neonates admitted to the neonatal intensive care unit (9). In current study we found the prevalence of CHD was $10.7 \%$ among neonates in neonatal intensive care unit that was higher according to literature. Higher frequency of emergence of CHD is an expected result, because of being sick babies, inspection of every day and more frequent evaluation of echocardiography in this group. In a study that performed on 3334 neonates in neonatal intensive care unit, the frequency was found to be $4 \%$. Heart murmur, central cyanosis and major congenital abnormalities were found statistically higher in the neonates with cardiac disorder (10). Archer et al. (11) reported that CHD is probably more frequent in very low birth infants treated in neonatal intensive care units than in the general live-born population. According to Aydogdu et al (12) and Shima et al (9) the most common cyanotic congenital heart disease was tetralogy of Fallot and the most common acyanotic heart disease was VSD in the neonatal intensive care unit. In our study results were same with those published reports.

Neonatal period because of the hemodynamic differences, 
there are difficulties in establishing the diagnosis of CHD. On the other hand, late diagnosis can be fatal in some cases (13). CHD may be associated with chromosomal abnormalities that are related to familial transition or part of syndromes (14). The clinical finding of $\mathrm{CHD}$ varies according to anatomic abnormalities in neonatal period. Besides severe symptoms such as respiratory distress, cyanosis and shock, murmur may be a single symptom.

In this study, we aimed to investigate the distribution, prevalence and pattern of various CHD in neonates followed in the neonatal intensive care unit at Abant Izzet Baysal University.

\section{Materials and Methods}

Among 326 cases admitted to the Abant Izzet Baysal University Neonatal Intensive Care Unit between February 2013 - September 2014, thirty-five newborns with CHDs were evaluated, retrospectively. The initial examination and evaluation of newborns were performed by newborns experts and patients were evaluated by a specialist pediatric cardiology if necessary. Echocardiography was performed to patients with abnormal heart murmur, abnormal electrocardiography findings, respiratory distress or cyanosis with unexplained pulmonary disease, Down's syndrome, dysmorphic features and diabetic mothers. The patients included in the study that was evaluated by echocardiography among sick babies in neonatal intensive care unit.

Interatrial septum opening less than $3 \mathrm{~mm}$ and the minimal patent ductus arterious (PDA) cases determined in the first three days (the cases of constant pressure difference between ductus arteriosus and pulmonary artery in doppler USG; and continuous minimal flow from left to right and no enlargement in the left ventricular and left atrial in colored doppler USG) were excluded in the study. Sociodemographic characteristics, perinatal characteristics, maternal history, physical examination, echocardiography results were recorded. Maternal age, miscarriage and stillbirth, brother history of CHD, diabetes, systemic lupus erythematosus (SLE), exposure to radiation, TORCH infection in pregnancy, smoking and alcohol use, intermarriage, CHD in the family were questioned.

Data was collected on a predesigned proforma containing information regarding gender, gestational age and weight at birth, family history, and associated malformations. SPSS was used for statistical analysis.

\section{Results}

The prevalence of CHD among infants admitted to our unit was $10.7 \%$. Non-cyanotic CHD was observed in 32 patients and cyanotic CHD was in 3 patients The most frequently isolated non-cyanotic heart diseases were, ventricular septal defect (VSD) atrial septal defect (ASD) and patent ductus arteriosus (PDA) respectively, while cyanotic CHDs as, transposition of the great arteries coarctation of the aorta and hypoplastic left heart syndrome (Table 1). One case was
Down syndrome. Maternal diabetes frequency was $17.1 \%$.

The most common cause for cardiology consultation was murmur $(85.5 \%)$. Cyanosis, respiratory distress, dysmorphic features and maternal diabetes were the other main reasons for the consultation. $62 \%$ of cases were born in our hospital. $40 \%$ of cases were female and $60 \%$ of were male. $51 \%$ of cases were premature (28-37 weeks), $49 \%$ of were mature (38-41 weeks). The birth weight was ranged between 10354290 gr. The average maternal age was $28 \pm 5$ year. Three parents $(8.5 \%)$ had consanguineous marriages and four parents $(11.4 \%)$ had miscarriage history. Two patients $(5.7 \%)$ had family history of CHD.

There was no history of SLE, alcohol or tobacco use during pregnancy, exposure to radiation in any mothers. One patient (\% 2.8) was diagnosed as Down syndrome and atrioventricular septal defect was detected in echocardiographic examination. Six patients with a diagnosis of CHD (17.1\%) had diabetes in their mother. Heart diseases in infants of diabetic mothers are presented in Table 2 and the most common finding was muscular VSD.

Table 1. The frequency of cyanotic and noncyanotic heart diseases.

\begin{tabular}{llll}
\hline Cardiac disease & isolated & $\begin{array}{l}\text { with other } \\
\text { cardiac diseases }\end{array}$ & total \\
\hline & $\mathrm{n}(\%)$ & $\mathrm{n}(\%)$ & $\mathrm{n}(\%)$ \\
VSD & $8(22.8)$ & $12(34.2)$ & $17(57)$ \\
ASD & $7(20)$ & $11(31.4)$ & $18(51.4)$ \\
PDA & $6(17.1)$ & $3(8.5)$ & $9(25.6)$ \\
$\begin{array}{l}\text { Transposition of the great } \\
\text { arteries }\end{array}$ & $1(2.8)$ & 0 & $1(2.8)$ \\
$\begin{array}{l}\text { Hypoplastic left heart } \\
\text { syndrome }\end{array}$ & $1(2.8)$ & 0 & $1(2.8)$ \\
Coarctation of the aorta & $1(2.8)$ & 0 & $1(2.8)$ \\
\hline
\end{tabular}

VSD: Ventricular septal defect, ASD: Atrial septal defect, PDA: Patent ductus arterious

Table 2. The frequency of congenital heart disease in infants of diabetic mothers.

\begin{tabular}{ll}
\hline Cardiac disease & n \\
\hline Muscular VSD & 3 \\
Secundum ASD & 2 \\
ASD+VSD & 1 \\
Total & 6 \\
\hline
\end{tabular}

VSD: Ventricular septal defect, ASD: Atrial septal defect

\section{Discussion}

CHDs are important major anomalies observed more common in neonatal period and may require immediate treatment. In current study we found that the frequency of CHD in hospitalize newborns was $10.7 \%$. Aydogdu et al was found $6.6 \%$ (12) and Guven et al 4.9\% (15). The prevalence of CHD was higher in this study than other reports; this may be due to high prematurity rate as $51 \%$. Aydogdu et al reported the prematurity rate as $18 \%(12)$. 
The incidence of CHDs is summarized in table 3.

Table 3. The incidence of congenital heart disease (16).

\begin{tabular}{ll}
\hline Lesion type & $\%$ \\
\hline VSD & $25-30$ \\
ASD (secundum) & $6-8$ \\
PDA & $6-8$ \\
Coarctation of the aorta & $5-7$ \\
Tetralogy of Fallot & $5-7$ \\
Pulmonary valve stenosis & $5-7$ \\
Aorta valve stenosis & $4-7$ \\
Transposition of the great arteries & $3-5$ \\
Hypoplastic left heart syndrome & $1-3$ \\
Truncus arterious & $1-2$ \\
Tricuspid atresia & $1-2$ \\
Single ventricle & $1-2$ \\
Double outlet right ventricle & $1-2$ \\
Others & $5-10$ \\
\hline
\end{tabular}

VSD: Ventricular septal defect, ASD: Atrial septal defect, PDA: Patent ductus arterious

This retrospective study showed that the most common reason for cardiology consultation was heart murmur. In the study of Aydogdu et al suggested that the most common reason for cardiology consultation was again murmur; alone or in combination with other signs with a ratio of $87.5 \%$ (12). In addition to pathological murmurs, the innocent systolic murmurs can be heard more than $50 \%$ of healthy and term infants in the first week (17).

VSD is most common defect among CHD with 25\% percent and seen $2.5 / 1000$ in live births. In our study, the most frequent CHD was VSD and among these patients the most common seen VSD type was small-medium with muscular VSD. VSD combined with other cardiac abnormalities were detected in $34.2 \%$ of infants. In the study of Aydogdu et al single VSD was found as the most frequent CHD (19.6\%) (12). Hussain et al found that the frequency of CHD among 5800 neonates in a neonatal unit of a tertiary care hospital was $\% 1.5$ with male preponderance and VSD was found to be most common defect (\%31.3), (18). VSD is usually asymptomatic and often closes spontaneously (19). The reported rates of spontaneous closure vary between $50 \%$ and $75 \%$ in small defects $(20-22)$. Therefore, the prevalence of VSD should be higher in neonates. Some studies done by performing echocardiography on newborns with no murmurs, have found huge numbers of tiny muscular VSD with the incidence of $2-5 \%(23,24)$. Roguin et al $(23)$ reported that the prevalence of muscular VSD in neonates of 53.2/1,000 live births and patients were asymptomatic, and $88.9 \%$ had defects that closed spontaneously within 1 to 10 months.

ASD represents $8-9 \%$ of CHD with the prevalence of $0.5 / 1000$ in live births. Many infants have a patent foramen ovale with a tiny left-to-right shunt, and inclusion of these will inflate the incidence of ASD. ASD is usually asymptomatic therefore murmurs are often soft; these defects frequently do not lead to early diagnosis or referral. Because diagnosed in adulthood, the incidence in childhood usually underestimates the true incidence of the lesion $(25,26)$. We found the incidence of ASD among neonates 51.4\%. 20\% of cases were isolated and $31.4 \%$ was combined with other cardiac defects.

PDA is another common defect which has an increased incidence among preterm infants with the prevalence of $10 \%$ among CHD. In term infant, the ductus arteriosus is almost always closed by four to seven days after birth. In current study $25.6 \%$ of neonates had PDA which was the third common defect that observed in neonatal intensive care unit. The reason for the high incidence may be due to high rate of prematurity in this study.

Atrioventricular septal defects (AVSDs) (endocardial cushion defects) have an incidence that varies with the age of the involved mothers. It's incidence is $0.20-0.25 / 1000$ of neonates in live births and creates $4-5 \%$ of CHD. Trisomy 21 (Down syndrome) is much more common in mothers more than 34 years old, and AVSDs are much more frequent in those with trisomy 21 than with normal chromosomes. Thus, the incidence of AVSDs increases in older mothers children. It is known that, $40 \%$ of children who was diagnosed as Down syndrome have CHD and most common defect is endocardial cushion defect (27). Reinhold et al (28) found that the genetic syndrome prevalence was 5.6\% among 814 patients with $\mathrm{CHD}$ and they reported the frequency of Down's syndrome was $1.4 \%$. In our study, this ratio was found to be $2.8 \%$. Aydogdu et al found the prevalence of Down syndrome as 3.6\% (12).

Coarctation of the aorta is an abnormality with the combination of upper body hypertension and weak or absent femoral pulses. But, studies in children's hospitals have shown that the diagnosis is often missed by the referring pediatric cardiologist (29). We found $2.8 \%$ of newborns with coarctation of the aorta among hospitalized neonates in the neonatal intensive care unit.

Transposition of the great arteries (TGA) is the most common form of $\mathrm{CHD}$, presenting within the first week of life. The aorta and the pulmonary artery take their origins from the right ventricle and left ventricle respectively. A dual parallel circulation exists were fully saturated blood from the pulmonary veins is returned to the pulmonary circulation, and desaturated blood from the systemic veins is returned to the systemic arterial circulation. This results life-threatening hypoxia in the newborn period. TGA affects $5 \%$ of infants with CHD with $90 \%$ of mortality within the first year of life (30). We observed 2.8\% TGA among hospitalized neonates.

Hypoplastic left heart syndrome is a rare congenital heart defect in which the left side of the heart is underdeveloped. It was previously regarded as fatal but surgical management of hypoplastic left heart syndrome has changed the prognosis (31). The incidence of this syndrome is $1-4 \%$ among CHD. We found $2.8 \%$ of our infants were with this syndrome.

In our study, $17.1 \%$ of infants with CHD had diabetic mothers and most common defect was muscular VSD among this infants. In general, asymmetric septal hypertrophy, VSD, ASD, pulmonary stenosis are common abnormality in infants of diabetic mothers (32). 
In conclusion, the incidence of CHD in newborns at the neonatal intensive care unit was higher than that in all live births. Its incidence varies from centre to centre due to different factors like nature of the sample, method of detection and early examination by a neonatologist / pediatrician. In this study a higher incidence is reported because it was carried out in a tertiary care unit and prematurity prevalence was higher. The most frequent diagnostic clue was cardiac murmur and the most frequently observed risk factors were maternal diabetes mellitus and genetic syndrome.

\section{Study Limitations}

We have carried out a small regional study; there is a need to establish a database for CHDs among sick babies in neonatal intensive care unit. Therefore further studies with the large number of neonates are recommended.

\section{References}

[1] Clur SA, Van Brussel PM, Mathijssen IB, Pajkrt E, Ottenkamp J, Bilardo CM. Audit of 10 years of referrals for fetal echocardiography. Prenat Diagn 2011; 31: 1134-1140.

[2] Lee JE, Jung KL, Kim SE, Nam SH, Choi SJ, Oh SY, Roh CR, Kim JH. Prenatal diagnosis of congenital heart disease: trends in pregnancy termination rate, and perinatal and 1-year infant mortalities in Korea between 1994 and 2005. J Obstet Gynaecol Res 2010; 36: 474-478.

[3] Yu Z, Xi Y, Ding W, Han S, Cao L, Zhu C, Wang X, Guo X. Congenital heart disease in a Chinese hospital: pre- and postnatal detection, incidence, clinical characteristics and outcomes. Pediatr Int 2011; 53: 1059-1065

[4] Friedberg MK, Silverman NH, Moon-Grady AJ, Tong E, Nourse J, Sorenson B, Lee J, Hornberger LK. Prenatal detection of congenital heart disease. J Pediatr 2009; 155: 2631

[5] Ozkutlu S, Akça T, Kafali G, Beksaç S. The results of fetal echocardiography in a tertiary center and comparison of lowand high-risk pregnancies for fetal congenital heart defects. Anadolu Kardiyol Derg 2010; 10: 263-269.

[6] Galindo A, Herraiz I, Escribano D, Lora D, Melchor JC, de la cruz J. Prenatal detection of congenital heart defects: a survey on clinical practice in Spain. Fetal Diagn Ther 2011; 29: 287295.

[7] Hoffman JI. Incidence of congenital heart disease: II. Prenatal incidence. Pediatr Cardiol 1995; 16: 155-165.

[8] Hoffman JI. Incidence of congenital heart disease: I. Postnatal incidence. Pediatr Cardiol 1995; 16: 103-113.

[9] Shima Y, Takechi N, Ogawa S, Fukazawa R, Fukumi D, Uchikoba Y, et al. Clinical characteristics of congenital heart disease diagnosed during neonatal period. J Nihon Med Sch 2001; 68: 510-515

[10] Hatipoğlu S, Salihoğlu Ö, Can E, Akyol MB. Clinical analysis of neonates with congenital heart disease in the neonatal intensive care unit: a 5-year experience. Anadolu Kardiyol Derg 2012; 12: 612-613.
[11] Archer JM, Yeager SB, Kenny MJ, Soll RF, Horbar JD. Distribution of and mortality from serious congenital heart disease in very low birth weight infants. Pediatrics 2011; 127: 293-299.

[12] Aydoğdu SA, Türkmen M, Özkan P. The Prevalence of Congenital Heart Disease in Newborns at Adnan Menderes University Neonatal Intensive Care Unit. ADÜ Tip Fakültesi Derg 2008; 9: 5-8.

[13] Flanagan MF, Yeager SB, Weindling SN. Cardiac disease. In: MacDonald MG, Seshia MMK, Mullet MD, editors. Avery's Neonatology Pathophysiology and Management of the Newborn, 6th ed. Lippincott,Williams andWilkins, Philadelphia, 2005: 633-709.

[14] Kazez A, Özel ŞK, Yılmaz E, Hanbeyoğlu A, Köseoğulları AA. The prevalans of congenital herath disease in children with inguinal hernia. Firat Medical Journal 2005; 10: 048-049.

[15] Güven H, Bakiler AR, Kozan M,Aydınoglu H, Helvacı M, Coşkun Dorak. Echocardiographic screening in newborn infants. Çocuk Saglıgı ve Hastalıkları Dergisi 2006; 49: 8-11.

[16] Bernstein D. Epidemiology and genetic basis of congenital heart disease. Nelson Texbook of Pediatrics (Ed. Berhman RE, Kliegman RM ,Jenson HB), 16.baskı, W.B. saunders Company, Philadephia 2000, 1499- 1502.

[17] Park MK. Manifestations of cardiac problems in the newborn. In: Park MK, editor. Pediatric Cardiology for Practitioners, 3rd ed. Mosby, St. Louis, 1996: 374-398.

[18] Hussain S, Sabir MU, Afzal M, Asghar I. Incidence of congenital heart disease among neonates in a neonatal unit of a tertiary carehospital. J Pak Med Assoc 2014; 64: 175-178.

[19] Newman TB. Etiology of ventricular septal defects: an epidemiologic approach. Pediatrics 1985; 76: 741-749.

[20] Moe DG, Guntheroth WG Sponteneous closure of uncomplicated ventricular septal defect Am J Cardiol 1987; 60: 674-678.

[21] Hoffman JIE. Natural history of congenital heart disease: problems in its assessment with special reference to ventricular septal defects. Circulation 1968; 37: 97-125.

[22] Alpert BS, Cook DH, Varghese J, Rowe RD. Spontaneous closure of small ventricular septal defects: ten years follow-up. Pediatrics 1979; 63: 204-206.

[23] Roguin N, Du ZD, Barak M, Nasser N, Hershkowitz S, Milgram E. High prevalence of muscular ventricular septal defect in neonates. J Am Coll Cardiol 1995; 26: 1545-1548.

[24] Sands AJ, Casey FA, Craig BG, Dornan JC, Rogers J, Mulholland HC. Incidence and risk factors for ventricular septal defect in "low risk" neonates. Arch Dis Child Fetal Neonatal Ed 1999; 81: F61-3

[25] Seldon WA, Rubinstein C, Fraser AA. The incidence of atrial septal defect in adults. Br Heart J 1962; 24: 557-560.

[26] Rostad H, Sørland SJ. Atrial septal defects of secundum type in patients less than 40 years of age. A follow-up study. Acta Med Scand Suppl 1981; 645: 29-35.

[27] Park MK. Left-to-right shunt lesions. In: Park MK, editor. Pediatric Cardiology for Practitioners, 3rd ed. Mosby, St. Louis, 1996: 145-146. 
[28] Reinhold-Richter L, Fischer A, Schneider-Obermeyer J. Congenital heart defects. Frequency at autopsy. Zentralbl Allg Pathol 1987; 133: 253-261

[29] Strafford MA, Griffiths SP, Gersony WM. Coarctation of the aorta: a study in delayed detection. Pediatrics 1982; 69: 159163.

[30] Liebman, J, Cullum, L, Belloc, NB (1969) Natural history of transposition of the great arteries. Anatomy and birth and death characteristics. Circulation 40: pp. 237-262
[31] Barron DJ, Kilby MD, Davies B, Wright JG, Jones TJ, Brawn WJ. Hypoplastic left heart syndrome. Lancet 2009; 374: 551564

[32] Abu-Sulaiman RM, Subaih B. Congenital heart disease in infants of diabetic mothers: Echocardiographic study. Pediatr Cardiol 2004; 25: 137-140. 